\title{
Management of Bell palsy: clinical practice guideline
}

\author{
John R. de Almeida MD MSc, Gordon H. Guyatt MD MSc, Sachin Sud MD MSc, Joanne Dorion PT BScPT, \\ Michael D. Hill MD, Michael R. Kolber MD MSc, Jane Lea MD, Sylvia Loong Reg PT, Balvinder K. Somogyi BSW, \\ Brian D. Westerberg MD MHSc, Chris White MD, Joseph M. Chen MD (Bell Palsy Working Group, Canadian \\ Society of Otolaryngology - Head and Neck Surgery and Canadian Neurological Sciences Federation)
}

$\mathrm{B}$ ell palsy is an idiopathic weakness or paralysis of the face of peripheral nerve origin, with acute onset. It affects 20-30 persons per 100000 annually, and 1 in 60 individuals will be affected over the course of their lifetime. ${ }^{1,2}$ The major cause of Bell palsy is believed to be an infection of the facial nerve by the herpes simplex virus. ${ }^{3}$ As a result of this viral infection, the facial nerve swells and is compressed in its canal as it courses through the temporal bone.

Recovery of facial nerve function is an important outcome that guides treatment recommendations. The initial severity of facial weakness provides valuable prognostic information for facial recovery. Commonly used facial grading instruments (e,g., House-Brackmann and Sunnybrook scales) quantify the severity of facial weakness. ${ }^{4,5}$ Patients with mild to moderate paresis have higher rates of recovery than those with severe or complete paresis. In a large, single-institution cohort study, recovery rates of $61 \%$ and $94 \%$ were documented in patients with complete and incomplete paralysis, respectively. ${ }^{6}$

Other important clinical outcomes exist in Bell palsy. Up to $16 \%$ of those affected will have residual involuntary movements known as synkinesis, ${ }^{7}$ whereas others may have abnormal lacrimation with eating, known as Bogorad syndrome (crocodile tears). Failure to protect the cornea among patients who are unable to blink adequately may result in corneal ulceration and permanent visual impairment. Those with residual deficits may have long-term reduction in quality of life and psychological distress. ${ }^{8}$

In this guideline, we review the evidence for treatment of Bell palsy with corticosteroids and antivirals, facial exercise, electrostimulation, physiotherapy and decompression surgery, as well as the need for eye-protective measures, specialist referral and further investigation in patients with persistent and progressive weakness.

This guideline is aimed at all health care providers, primarily front-line or primary care physicians who treat patients with Bell palsy.

\section{Methods}

We generated recommendations (specifically by rating the importance of outcomes, rating the confidence of effect estimates and grading recommendations) in accordance with methods proposed by the Grading of Recommendations Assessment, Development and Evaluation (GRADE) system for the development of clinical practice guideline recommendations (Box 1). ${ }^{9-13}$ We applied the AGREE appraisal tool for clinical practice guidelines. ${ }^{14}$

\section{Panel composition and organization}

A working group of 11 members was assembled under the auspices of the Canadian Society of Otolaryngology - Head and Neck Surgery and the Canadian Neurological Sciences Federation. The group consisted of three methodologists (J.D.A., G.H.G., S.S.), three otolaryngology - head and neck surgeons (J.D.A., B.D.W., J.M.C.), two neurologists (M.D.H., C.W.), one family physician (M.R.K.), two facial nerve therapists (J.D., S.L.) and one patient (B.K.S.). An additional methodologist (J.L.) was involved in the review process but not in developing the guideline recommendations. We developed the guidelines through a series of four conference calls and extensive email correspondence between January 2010 and June 2012.

\section{Management of conflicts of interest}

Group members disclosed financial and intellectual conflicts of interest. Each potential conflict
Competing interests: See end of article for competing interests.

This article has been peer reviewed.

Correspondence to: John de Almeida, john.dealmeida@utoronto.ca CMAJ 2014. DOI:10.1503 /cmaj.131801

\section{KEY POINTS}

- Preliminary assessment of a patient with Bell palsy should include physical examination, to rule out other causes of facial weakness, and a grading of severity of weakness, to determine further treatment.

- Unless contraindicated, corticosteroids should be given to all patients with Bell palsy; antivirals may be considered for patients with severe to complete paresis.

- Patients with incomplete eye closure should be given eye protection, with lubricating drops and ointments, to prevent corneal damage.

- For patients with persistent or progressive facial weakness, imaging of the course of the facial nerve, referral to a specialist for further diagnostic considerations and referral to a facial therapist for facial physiotherapy should be considered. 
of interest was evaluated to determine whether it was acceptable or unacceptable (which would preclude participation). Panel members with acceptable conflicts of interest were permitted to participate in collecting and interpreting evidence but were not involved in deliberations for recommendations related to their conflicts. ${ }^{15}$

\section{Guideline development methods}

We drafted a list of topics to be addressed by the guideline (Table 1). The primary outcome for this analysis was unsatisfactory facial motor recovery (House-Brackmann score of grade 3-6 or equivalent). Secondary outcomes included synkinesis, autonomic dysfunction, pain, poor quality of life, loss of vision and adverse effects. Although other facial outcomes such as synkinesis and autonomic dysfunction may be considered to represent unsatisfactory recovery, we defined them separately from the primary outcome. We identified outcomes deemed important to patients at the outset of the guideline development process. The process to determine the importance of each topic or outcome followed the GRADE process (Box 1).

We identified relevant systematic reviews for each topic by searching PubMed and MEDLINE through June 2011 and selected one previously published systematic review for each topic on the basis of methodologic quality, number of studies included and most recent publication. We conducted new reviews for topics for which no systematic review was available, we updated reviews for those published more than two years before the start of the guideline development process, and we conducted new reviews addressing cost-utility and

Box 1: Notes on the Grading of Recommendations Assessment, Development and Evaluation (GRADE) recommendation process ${ }^{9-13}$

This guideline was informed by a systematic review and was developed in accordance with the methods proposed by the GRADE Working Group:

- We rated the importance of each outcome as not important, important or critical. Each panel member rated each outcome on a scale from 1 to 9, and we classified mean scores from 1 to 3 as not important, from 4 to 6 as important but not critical and from 7 to 9 as critical.

- We rated the confidence in effect estimates for each outcome as very low, low, moderate or high on the basis of factors that decrease or increase confidence in effect estimates. Factors that can decrease the confidence in effect estimates include risk of bias, inconsistency of results, indirectness of evidence, imprecision and publication bias. Factors that can increase the confidence in effect estimates include large magnitude of effect, plausible confounding that would reduce a demonstrated effect and a dose-response gradient.

- When rating the overall confidence in effect estimate for any recommendation (Table 1), we considered only critical outcomes. We determined the overall confidence in effect estimate for any recommendation by taking the lowest confidence in effect estimate rating of any critical outcome for that recommendation.

- We categorized recommendations as strong or weak on the basis of four factors: balance of desirable and undesirable consequences, confidence in effect estimates for the critical outcomes, variability in patient values and preferences, and implications regarding resource use. patient values and preferences. For treatments or outcomes for which data were heterogeneous and outcome measures differed, we did not perform meta-analysis. A description of the full methodology and the complete guideline can be found in Appendix 1, available at www.cmaj.ca/lookup /suppl/doi:10.1503/cmaj.131801/-/DC1.

\section{Recommendations}

A clinical decision-making algorithm summarizing the recommendations appears in Figure 1.

1. We recommend the use of corticosteroids for all patients with Bell palsy. (Strong recommendation: moderate confidence in effect estimate.)

Corticosteroids reduce the risk of unsatisfactory facial recovery (relative risk [RR] 0.69, 95\% confidence interval [CI] $0.55-0.87),{ }^{16}$ with a number needed to treat (NNT) of 50 for patients with mild to moderate paresis and 8 for patients with severe to complete paralysis. These drugs significantly reduce synkinesis (RR 0.56, 95\% CI 0.41-0.76), with no apparent increase in the risk of adverse effects. A subgroup analysis suggested an improved effect with a total prednisone equivalent dose of $450 \mathrm{mg}$ or higher. ${ }^{16}$ Although the window of treatment is unclear, a subgroup analysis of one randomized controlled trial suggested a benefit only if administered within 48 hours of onset. ${ }^{17}$ Given the proven cost-effectiveness of corticosteroids, ${ }^{18}$ clinicians can encourage their use for all patients who do not have any medical contraindications.

\section{We recommend against antiviral treatment} alone. (Strong recommendation: moderate confidence in effect estimate.)

A meta-analysis showed no reduction in the RR of unsatisfactory recovery with antivirals (RR 1.14, 95\% CI 0.80-1.62) or in the risk of synkinesis with antivirals (RR 1.04, 95\% CI 0.75-1.43). ${ }^{16}$ However, there was no increase in major (RR $0.50,95 \%$ CI 0.05-5.40) or minor (RR 0.85, 95\% CI 0.56-1.29) adverse effects. Administration of antivirals is more costly than no therapy. ${ }^{18}$ There is no reason to offer this treatment in isolation to patients with Bell palsy.

3. We suggest against the addition of antivirals to corticosteroids for patients with mild to moderate severity. (Weak recommendation: moderate confidence in effect estimate.)

There is a potential reduction in the risk of unsatisfactory facial recovery (RR $0.75,95 \%$ CI 0.56-1.00) and synkinesis (RR $0.59,95 \% \mathrm{CI}$ 0.39-0.89) with combined treatment relative to steroids alone. ${ }^{16}$ However, for patients with mild to moderate paresis, the NNT for one fewer episode of unsatisfactory facial recovery is 100 . 
Furthermore, the addition of antiviral therapy to corticosteroid monotherapy is unlikely to be cost-effective. ${ }^{18}$ Patients who place a very high value on avoiding synkinesis are likely to choose to use antivirals in addition to corticosteroids.

4. We suggest the combined use of antivirals and corticosteroids in patients with severe to complete paresis. (Weak recommendation: moderate confidence in effect estimate.)

With an RR for unsatisfactory recovery of 0.75 (95\% CI $0.56-1.00)$, the NNT to prevent one unsatisfactory recovery is 14 in patients with severe to complete paresis. ${ }^{16}$ The optimal dosing regimen is uncertain, although acyclovir $400 \mathrm{mg}$ given five times daily or valacyclovir $1 \mathrm{~g}$ given three times daily is common in most studies.

5. We make no recommendation regarding the use of exercise physiotherapy for acute Bell palsy of any severity. (No recommendation: very low confidence in effect estimate.)

Three studies were included in a systematic review evaluating the use of exercise physiotherapy; however, the confidence in effect estimates was very low because of risk of bias, indirectness and imprecision. ${ }^{19-21}$ Given the heterogeneous results in these studies, our working group was unable to achieve consensus regarding exercise physiotherapy.

6. We suggest exercise physiotherapy for patients with persistent weakness. (Weak recommendation: very low confidence in effect estimate.)

We identified one observational study evaluating the use of exercise physiotherapy for patients who did not have complete facial recovery. ${ }^{22} \mathrm{We}$ rated our confidence in the effect estimate as very low because of a serious risk of bias and imprecise results. The single nonrandomized study evaluated two groups, one of which received exercise, stretching and massage physiotherapy, and the other of which did not. Patients in the physiotherapy group had significantly improved facial function as measured by House-Brackman scores (mean difference 0.6, 95\% CI 0.1-1.1).

\section{We suggest against the use of electrostimula-} tion. (Weak recommendation: very low confidence in effect estimate.)

A systematic review identified four studies. ${ }^{23-26}$ Three of the studies (one comparing electrostimulation with massage, ${ }^{23}$ one comparing electrostimulation with corticosteroids, ${ }^{24}$ and one comparing heat, massage, exercises and electrostimulation with the same treatments excluding electrostimulation ${ }^{26}$ )

Table 1: Summary of topics and recommendations

\begin{tabular}{|c|c|c|c|c|}
\hline Treatment & Severity & Recommendation & Strength & $\begin{array}{l}\text { Confidence in } \\
\text { effect estimate }\end{array}$ \\
\hline Corticosteroids & Any severity & $\begin{array}{l}\text { We recommend the use of corticosteroids for all } \\
\text { patients with Bell palsy. }\end{array}$ & Strong & Moderate \\
\hline Antivirals & Any severity & We recommend against antiviral treatment alone. & Strong & Moderate \\
\hline \multirow[t]{2}{*}{$\begin{array}{l}\text { Corticosteroids + } \\
\text { antivirals }\end{array}$} & $\begin{array}{l}\text { Mild to moderate } \\
\text { paresis }\end{array}$ & $\begin{array}{l}\text { We suggest against the addition of antivirals to } \\
\text { corticosteroids for patients with mild to moderate } \\
\text { severity. }\end{array}$ & Weak & Moderate \\
\hline & $\begin{array}{l}\text { Severe to complete } \\
\text { paresis }\end{array}$ & $\begin{array}{l}\text { We suggest the combined use of antivirals and } \\
\text { corticosteroids in patients with severe to complete } \\
\text { paresis. }\end{array}$ & Weak & Moderate \\
\hline \multirow[t]{2}{*}{$\begin{array}{l}\text { Exercise } \\
\text { physiotherapy }\end{array}$} & Acute; any severity & $\begin{array}{l}\text { We make no recommendation regarding the use } \\
\text { of exercise physiotherapy for acute Bell palsy of } \\
\text { any severity. }\end{array}$ & $\begin{array}{l}\text { Not } \\
\text { applicable }\end{array}$ & Very low \\
\hline & Chronic & $\begin{array}{l}\text { We suggest exercise physiotherapy for patients } \\
\text { with persistent weakness. }\end{array}$ & Weak & Very low \\
\hline Electrostimulation & Acute; any severity & We suggest against the use of electrostimulation. & Weak & Very low \\
\hline $\begin{array}{l}\text { Surgical } \\
\text { decompression }\end{array}$ & $\begin{array}{l}\text { Severe to complete } \\
\text { paresis }\end{array}$ & $\begin{array}{l}\text { We suggest against the routine use of surgical } \\
\text { decompression. }\end{array}$ & Weak & Very low \\
\hline $\begin{array}{l}\text { Eye-protective } \\
\text { measures for } \\
\text { incomplete eye } \\
\text { closure }\end{array}$ & $\begin{array}{l}\text { Any severity, with } \\
\text { incomplete eye } \\
\text { closure }\end{array}$ & $\begin{array}{l}\text { We recommend the routine use of eye-protective } \\
\text { measures for patients with incomplete eye closure. }\end{array}$ & Strong & Very low \\
\hline $\begin{array}{l}\text { Referral to } \\
\text { specialist }\end{array}$ & Progressive cases & $\begin{array}{l}\text { We recommend referral to a specialist for patients } \\
\text { with no improvement or progressive weakness. }\end{array}$ & Strong & Very low \\
\hline $\begin{array}{l}\text { Work-up for } \\
\text { neoplasm }\end{array}$ & Progressive cases & $\begin{array}{l}\text { We recommend imaging to rule out neoplasms or } \\
\text { alternative diagnoses for patients with no } \\
\text { improvement or progressive weakness. }\end{array}$ & Strong & Very low \\
\hline
\end{tabular}


showed no benefit in facial recovery. However, one randomized study showed significantly poorer facial recovery with electrostimulation than with facial exercise. ${ }^{25}$ The available very-low-quality evidence provides little support for electrostimulation; in addition, the safety profile of such therapy is unproven, and there is an added cost.

8. We suggest against the routine use of surgical decompression. (Weak recommendation: very low confidence in effect estimate.)

For studies identified in a systematic review, we had very low confidence in the effect estimates because of serious methodologic limitations (specifically nonrandomization) and the imprecision and indirectness of results. The surgical approaches studied were heterogeneous, with only two of six studies involving decompression of the labyrinthine segment (meatal foramen), the pre-

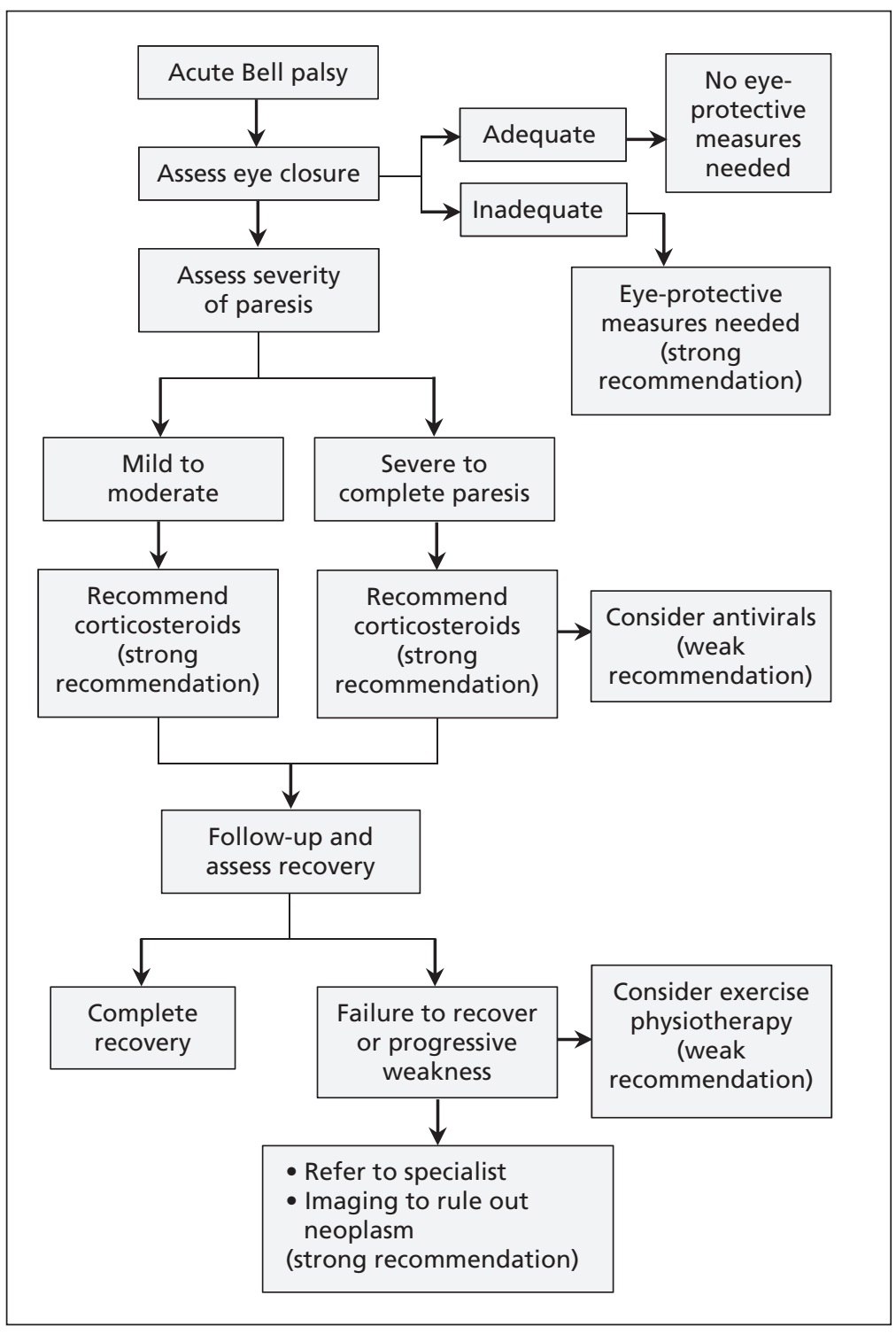

Figure 1: Clinical decision-making algorithm for acute Bell palsy. sumed site of the lesion in Bell palsy, through a middle cranial fossa surgical approach..$^{27,28}$ One nonrandomized study of patients who were offered surgery showed a significant benefit of surgery relative to those treated medically $(91 \% \mathrm{v}$. $42 \%$ chance of a fair recovery) ${ }^{27}$ Surgical decompression has potentially serious risks, including hearing loss ( $3 \%-10 \%$ of patients), ${ }^{27-29}$ further damage to the facial nerve (unknown prevalence) and leaks of cerebrospinal fluid (4\%). ${ }^{27}$ Patients should consider this option only if they have severe facial nerve degeneration on electroneuronography, if they are willing to accept the surgical risks and if the surgery is to be performed in an advanced treatment facility.

9. We recommend the routine use of eye-protective measures for patients with incomplete eye closure. (Strong recommendation: very low confidence in estimates.)

We identified no randomized or observational studies comparing visual outcomes with and without eye-protective measures. We rated our confidence in the effect estimate as very low because of the absence of available evidence. However, inadequate lubrication or hydration of the cornea can lead to exposure keratitis, corneal ulceration and eventually loss of vision.

10. We recommend referral to a specialist for patients with no improvement or progressive weakness. (Strong recommendation: very low confidence in estimates.)

We identified no randomized or observational studies comparing outcomes for patients with Bell palsy who were and were not referred to a specialist. Therefore, our confidence in the effect estimates was very low. For patients with no improvement in facial nerve function or progression of facial nerve paralysis, referral to an otolaryngologist may be reasonable to confirm the diagnosis and to exclude other conditions. Referral to a specialist may avoid missed diagnoses of malignant skull-base neoplasms $^{30}$ or benign facial nerve schwannomas, ${ }^{31}$ which may masquerade as Bell palsy. The possibly catastrophic consequences of having a serious condition that mimics Bell palsy, albeit rare, and the unlikely serious harm associated with referral, motivate this strong recommendation.

11. We recommend imaging to rule out neoplasms or alternative diagnoses for patients with no improvement or progressive weakness. (Strong recommendation: very low confidence in effect estimate.)

We identified no randomized or observational studies investigating the role of imaging for neoplasms in patients with Bell palsy. Therefore, our 
confidence in the effect estimate was very low. For patients with no response to initial treatment and progressive facial paralysis, investigation for neoplasms along the course of the facial nerve should include imaging of the course of the facial nerve (brain stem, temporal bone, parotid gland) with either magnetic resonance imaging (MRI) or highresolution computed tomography (CT). We found no trials comparing various imaging techniques for progressive facial nerve dysfunction, but each technique has its own merits. ${ }^{32}$ MRI may be better suited to evaluating the brain stem, cerebellopontine angle, interfaces between bone and soft tissues, and the parotid gland, whereas high-resolution CT may be more widely available and better suited for studying the intratemporal segment of the nerve. ${ }^{33}$

\section{Implementation}

Implementation of these guidelines will be facilitated through publication and access to relevant materials through the Canadian Society of Otolaryngology - Head and Neck Surgery and the Canadian Neurological Sciences Federation. To aid in utilization of these guidelines, representatives of pertinent health care stakeholders have been involved in the guideline-development process, and relevant professional organizations were invited to review and/or endorse the guideline. The guideline will be updated in five years, with a plan to review the new interim evidence and update the existing recommendations.

\section{Other guidelines}

A concurrent guideline was recently published by the American Academy of Otolaryngology - Head and Neck Surgery..$^{34}$ That guideline, by Baugh and colleagues, had a similar scope and some similarities in recommendations, but there were notable differences. The target audience included all treating providers, whereas our guideline is aimed mainly at primary care physicians. The other guideline also focused on diagnostic work-up of Bell palsy, whereas ours focused mainly on treatment issues. We have recommended combined corticosteroid and antiviral therapy only for patients with severe to complete paralysis. Baugh and colleagues recommended combined treatment as an option in all cases and did not consider specific subgroups independently for these recommendations. We have also recommended that facial physiotherapy may be indicated for patients with long-standing paresis who have experienced no improvement, whereas Baugh and colleagues did not consider this specific subpopulation and did not make a recommendation for physiotherapy in acute cases. This difference may be attributable to differences in the panel com- position. Finally, Baugh and associates did not make a recommendation about surgical decompression. We felt that given the balance of possible beneficial and harmful outcomes and the available evidence, decompression should not be routinely performed.

A Quality Standards Subcommittee of the American Academy of Neurology issued a practice parameter in 2001, concluding that there was insufficient evidence to support the use of corticosteroids, antiviral agents or surgical decompression for Bell palsy. ${ }^{35} \mathrm{~A}$ recent update of this guideline advocated the use of corticosteroids and concluded that antivirals may be of modest benefit. ${ }^{36}$ Of two other treatment guidelines, one concluded that there was insufficient evidence to give corticosteroids to children $^{37}$ and the other suggested use of corticosteroids on the basis of a narrative review of the available evidence..$^{38}$ The present guideline used the GRADE methodology and offers recommendations addressing nonmedical therapeutic options that have been omitted from other guidelines.

\section{Gaps in knowledge}

Gaps in the available evidence have implications for the current recommendations. Although moderate-quality evidence exists for medical treatment with corticosteroids and antiviral agents, our confidence in estimates for all relevant patientimportant outcomes from surgery and physiotherapy was very low. According to the GRADE approach, recommendations should also be based on evidence of values and preferences of patients with the disease condition, as well as information about costs and resource allocation. However, we identified no studies for Bell palsy investigating the values and preferences of patients and only one study that examined costs of corticosteroids and antivirals for Bell palsy. Further research is needed in these areas.

\section{Conclusion}

Although many patients with Bell palsy will experience improvement in their facial nerve function without treatment, persistent facial weakness can have implications for quality of life. Establishing the correct diagnosis is imperative to avoid missing another treatable condition. Choosing the correct treatment options for suitable patients can optimize the likelihood of recovery. The current guidelines are based on the best available evidence for treatment and diagnosis of Bell palsy.

\section{References}

1. Holland NJ, Weiner GM. Recent developments in Bell's palsy. BMJ 2004;329:553-7.

2. Hauser WA, Karnes WE, Annis J, et al. Incidence and prognosis 
of Bell's palsy in the population of Rochester, Minnesota. Mayo Clin Proc 1971;46:258-64.

3. Adour KK, Bell DN, Hilsinger RL Jr. Herpes simplex virus in idiopathic facial paralysis (Bell palsy). JAMA 1975;233:527-30.

4. House JW, Brackmann DE. Facial nerve grading system. Otolaryngol Head Neck Surg 1985:93:146-7.

5. Ross BG, Fradet G, Nedzelski JM. Development of a sensitive clinical facial grading system. Otolaryngol Head Neck Surg 1996;114:380-6.

6. Peitersen E. The natural history of Bell's palsy. Am J Otol 1982; 4:107-11.

7. Peitersen E. Bell's palsy: the spontaneous course of 2500 peripheral facial nerve palsies of different etiologies. Acta Otolaryngol Suppl 2002;(549):4-30.

8. Weir AM, Pentland B, Murray J, et al. Bell's palsy: the effect on self-image, mood state and social activity. Clin Rehabil 1995;9:121-5

9. Guyatt GH, Oxman AD, Vist GE, et al. GRADE: an emerging consensus on rating quality of evidence and strength of recommendations. BMJ 2008;336:924-6.

10. Guyatt GH, Oxman AD, Vist GE, et al. GRADE: What is "quality of evidence" and why is it important to clinicians? BMJ 2008;336:995-8.

11. Guyatt GH, Oxman AD, Kunz R, et al. GRADE: going from evidence to recommendations. BMJ 2008;336:1049-51.

12. Guyatt GH, Oxman AD, Kunz R, et al. GRADE: incorporating considerations of resources use into grading recommendations. BMJ 2008;336:1170-3

13. Jaeschke R, Guyatt GH, Dellinger P, et al. Use of GRADE grid to reach decision on clinical practice guidelines when consensus is elusive. BMJ 2008;337:a744.

14. Brouwers MC, Kho ME, Browman GP, et al. Development of the AGREE II, part 1: performance, usefulness and areas for improvement. CMAJ 2010;182:1045-52.

15. Guyatt G, Akl EA, Hirsh J, et al. The vexing problem of guidelines and conflict of interest: a potential solution. Ann Intern Med 2010;152:738-41.

16. de Almeida JR, Al Khaboi M, Guyatt GH, et al. Combined corticosteroid and antiviral treatment for Bell palsy: a systematic review and meta-analysis. JAMA 2009;302:985-93.

17. Axelsson S, Berg T, Jonsson L, et al. Prednisolone in Bell's palsy related to treatment start and age. Otol Neurotol 2011;32:141-6.

18. Hernández RA, Sullivan F, Donnan P, et al. Economic evaluation of early administration of prednisolone and/or acyclovir for the treatment of Bell's palsy. Fam Pract 2009;26:137-44.

19. Barbara M, Antonini G, Vestri A, et al. Role of Kabat physical rehabilitation in Bell's palsy: a randomized trial. Acta Otolaryngol 2010;130:167-72.

20. Wang XH, Zhang LM, Han M, et al. Clinical application of functional exercise and staged therapy in treatment of facial nerve paralysis [article in Chinese]. Zhonghua Linchuang Kangfu Zazhi 2004;8:616-7.

21. Wen CM, Zhang BC. Effect of rehabilitation training at different degree in the treatment of idiopathic facial palsy: a randomized controlled comparison. Zhongguo Linchuang Kangfu 2004:8:2446-7.

22. Beurskens CHG, Heymans PG. Mime therapy improves facial symmetry in people with long-term facial nerve paresis: a randomized controlled trial. Aust J Physiother 2006;52:177-83.

23. Mosforth J, Taverner D. Physiotherapy for Bell's palsy. BMJ 1958;2:675-7

24. Flores PF, Medina RZ, Haro LG. Idiopathic peripheral facial paralysis treatment physic therapy versus prednisone [article in Spanish]. Rev Med Inst Mex Seguro Soc 1998;36:217-21.

25. Manikandan N. Effet of facial neuromuscular re-education on facial symmetry in patients with Bell's palsy: a randomized controlled trial. Clin Rehabil 2007;21:338-43.

26. Alakram P, Puckree T. Effects of electrical stimulation on HouseBrackmann scores in early Bell's palsy. Physiother Theory Pract 2010;26:160-6

27. Gantz BJ, Rubinstein JT, Gidley P, et al. Surgical management of Bell's palsy. Laryngoscope 1999;109:1177-88

28. Fisch U. Surgery for Bell's palsy. Arch Otolaryngol 1981;107:1-11.

29. Brown JS. Bell's palsy: a 5-year review of 174 consecutive cases: an attempted double blind study. Laryngoscope 1982;92:1369-73.

30. Marzo SJ, Leonetti JP, Petruzzelli G. Facial paralysis caused by malignant skull base neoplasms. Neurosurg Focus 2002;12:e2.

31. Zhang R, Liu JP, Dai C. Misdiagnosis of facial nerve tumor [article in Chinese]. Zhonghua Er Bi Yan Hou Tou Jing Wai Ke Za Zhi 2007;42:817-20

32. Raghavan P, Mukherjee S, Phillips CD. Imaging of the facial nerve. Neuroimaging Clin N Am 2009;19:407-25.

33. Schwaber MK, Zealear D, Netterville JL, et al. The use of magnetic resonance imaging with high-resolution $\mathrm{CT}$ in the evaluation of facial paralysis. Otolaryngol Head Neck Surg 1989;101:449-58. 34. Baugh RF, Basura GJ, Ishii LE, et al. Clinical practice guideline: Bell's palsy. Otolaryngol Head Neck Surg 2013;149(3 Suppl): S1-27.

35. Grogan PM, Gronseth GS. Practice parameter: steroids, acyclovir, and surgery for Bell's palsy (an evidence-based review) report of the quality standards subcommittee of the American Academy of Neurology. Neurology 2001;56:830-6.

36. Gronseth GS, Paduga R. Evidence-based guideline update: steroids and antivirals for Bell palsy: report of the Guideline Development Subcommittee of the American Academy of Neurology. Neurology 2012;79:2209-13.

37. Lunan R, Nagarajan L. Bell's palsy: a guideline proposal following a review of practice. J Paediatr Child Health 2008;44:219-20.

38. Murthy JM, Saxena AB. Bell's palsy: treatment guidelines. Ann Indian Acad Neurol 2011;14(Suppl 1):S70-2.

Competing interests: Michael Hill has served as a board member of the Heart and Stroke Foundation (Alberta, NWT \& Nunavut) and an advisory board member for the Institute for Circulatory and Respiratory Health (Canadian Institutes of Health Research). For work outside the scope of this guideline, he has received consultancy fees from Vernalis Group Ltd. and Merck Ltd.; grant funding from Hoffmann-La Roche Canada Ltd.; payments for lectures from Hoffmann-La Roche Canada Ltd., Servier Canada and BMS Canada; and salary awards from the Heart and Stroke Foundation (Alberta, NWT \& Nunavut) and Alberta Innovates Health Solutions. He also owns stock in Calgary Scientific Inc., a technology software company in imaging (unrelated to the topic of this guideline). Sylvia Loong has received consultancy fees from Back in Action Physiotherapy (outside the scope of this guideline). No other competing interests were declared.

Affiliations: Department of Otolaryngology, Head and Neck Surgery (de Almeida), Princess Margaret Hospital, University of Toronto, Toronto, Ont.; Department of Medicine (Guyatt), McMaster University, Hamilton, Ont.; Institute for Better Health and Division of Critical Care (Sud), Department of Medicine, Trillium Health Partners, University of Toronto, Mississauga, Ont.; Facial Rehabilitation (Dorion) and Department of Otolaryngology Head and Neck Surgery (Chen), Sunnybrook Health Sciences Centre, Toronto, Ont.; Department of Clinical Neurosciences, Hotchkiss Brain Institute (Hill), and Department of Clinical Neurosciences, Faculty of Medicine (White), University of Calgary, Calgary, Alta; Department of Family Medicine (Kolber), University of Alberta, Peace River, Alta.; Department of Surgery (Lea, Westerberg), Division of Otolaryngology - Head and Neck Surgery, University of British Columbia, Vancouver, BC; St. Paul's Rotary Hearing Clinic (Lea, Westerberg), Vancouver, BC; Back in Action Physiotherapy (Loong), Markham, Ont.; patient with Bell palsy (Somogyi), Toronto, Ont.; Division of Otolaryngology - Head and Neck Surgery, University of Toronto (Chen), Toronto, Ont.

Contributors: John de Almeida led the process of guideline development. Gordon Guyatt and Joseph Chen helped with organizing the guideline process, determined relevance of conflicts of interest and oversaw guideline development from inception to completion. Gordon Guyatt also chaired the conference calls. John de Almeida, Sachin Sud, Jane Lea and Chris White were involved in updating or performing new systematic reviews and generating summary tables. All authors contributed to identifying relevant topics and outcomes, interpreting available evidence, discussing the data, generating the recommendations and drafting the manuscript.

Endorsements: Canadian Society of Otolaryngology - Head and Neck Surgery, Canadian Neurological Sciences Federation.

Funding: This manuscript had no grant funding. All organization and publication costs were internally funded.

Acknowledgements: The authors are grateful to the Canadian Society of Otolaryngology - Head and Neck Surgery and the Canadian Neurological Sciences Federation for their support in developing the guideline. 